\title{
Fractionation of Membranes from Metschnikowia reukaufii Protoplasts. Evidence for a Plasma-membrane-bound ATPase
}

\author{
By BIRGITT ALDERMANN AND MILAN HÖFER* \\ Botanisches Institut der Universität, Kirschallee 1, 5300 Bonn 1, FRG
}

(Received 8 August 1983; revised 26 October 1983)

\begin{abstract}
Cells of the yeast Metschnikowia reukaufii were transformed to true protoplasts by means of snail gut enzyme. The plasma membrane of purified protoplasts was labelled either by $\left[{ }^{3} \mathrm{H}\right]$ dansyl chloride or by $\mathrm{Na}^{125} \mathrm{I}$. The crude lysate of osmotically ruptured protoplasts was fractionated by two subsequent centrifugations on sucrose density gradients. The two protein peaks obtained at densities of 1.16 and $1.13 \mathrm{~g} \mathrm{~cm}^{-3}$ were identified according to their characteristic markers (radioactivity, cytochrome $c$ oxidase, oligomycin-sensitive ATPase at $\mathrm{pH} 8 \cdot 5$, and sterol content) as mitochondrial and plasma-membrane fractions, respectively. The ATPase activity associated with the plasma-membrane fraction exhibited a pH optimum at 6.5 , was insensitive to oligomycin and was inhibited by vanadate. It can therefore be used as an intrinsic plasmamembrane marker.

Adherence of silica microbeads to the protoplasts effectively increased the density of the plasma membrane so that it could be obtained in a purified state by a single density gradient centrifugation. A third ATPase, presumably associated with the tonoplast membrane, was also demonstrated.
\end{abstract}

\section{INTRODUCTION}

The primary cellular energy carrier is ATP, which is the product of membrane-bound oxidative phosphorylation. According to the chemiosmotic theory proposed by Mitchell (1963, 1967) the energy released by oxidation of a suitable organic substrate can be transduced into an electrochemical potential difference of protons across the plasma membrane, which, in turn, can be used to drive active transport of other substances into the cell by the so-called $\mathrm{H}^{+}$-symport (Harold, 1977; Eddy, 1982). The $\mathrm{H}^{+}$-symport has also been demonstrated in the yeast Metschnikowia reukaufii for the uptake of monosaccharides (Aldermann \& Höfer, 1981).

In a eukaryote such as yeast a distinct $\mathrm{H}^{+}$-translocating, ATP-splitting ATPase in the plasma membrane has to be postulated in addition to the reversible one of mitochondria. Such ion-translocating plasma-membrane-bound ATPases have been isolated from animal cells (Robinson \& Flashner, 1979; Verma \& Penniston, 1981), from plant cells (Galbraith \& Northcote, 1977; Perlin \& Spanswick, 1980) and from fungi (Goffeau \& Slayman, 1981).

It was the aim of the present work to isolate the plasma membrane from the yeast $M$. reukaufii in order to gain a better insight into the molecular mechanism of the energy-coupling between the ATP-splitting as the energy-delivering system (generation of the electrochemical $\mathrm{H}^{+}$gradient by means of the plasma-membrane-bound ATPase) and the 'uphill' plasma-membrane transport as the energy-consuming system $\left(\mathrm{H}^{+} /\right.$substrate symport $)$. The first difficulty encountered in isolating plasma membranes from plants, algae and fungi is due to the presence of a rigid cell wall. A rough mechanical disruption of whole cells can be avoided by preparation of osmotically-labile protoplasts. The method of enzymic digestion of the wall, followed by

Abbreviation: $\mathrm{PTACrO}_{3}$, phosphotungstic acid-chromic acid. 
osmotic lysis of the resultant protoplasts and differential and/or density gradient centrifugation of the lysate, has been frequently used recently. This more laborious but gentle way of cell disruption via protoplasts offers another major advantage by allowing specific labelling of the plasma membrane with radioactive markers.

In this paper we also describe a method for the attachment of silica microbeads to the protoplasts, to effectively increase the relative density of the plasma membrane so that it can be easily separated from the other membranes.

\section{METHODS}

Preparation of protoplasts. The facultatively anaerobic yeast $M$. reukaufii (Candida reukaufii, CBS 5834) was grown and harvested as before (Aldermann \& Höfer, 1981).

Protoplasts were prepared and purified as shown in Fig. 1 from cells harvested in the second half of the exponential growth phase (15 to $17 \mathrm{~h}$ growth, cf. Aldermann \& Höfer, 1981). Cell walls were digested by helicase, an enzyme mixture from snail gut (Helix pomatia) as proposed by Anderson \& Millbank (1966), Longley et al. (1968), Villanueva \& Garcia-Acha (1971), and Wiley (1974). Successful preparation of protoplasts from $M$. reukaufii required the addition of DTT and EDTA. The thiol reagent facilitated the cell wall digestion by reducing the disulphide bridges in the outer mannan-protein layer (Schwencke et al., 1977; Torres-Bauzá \& Riggsby, 1980). EDTA prevented aggregation of those protoplasts already formed (Wiemken \& Dürr, 1974; Thomas \& Davis, 1980). Under these conditions cells were completely and reproducibly converted to protoplasts after 2 to $2.5 \mathrm{~h}$ incubation with helicase.

The resulting protoplasts were separated from the enzyme by washing twice in $1 \mathrm{M}$-sorbitol, followed by separation from cell wall residues and cell debris on a density gradient. Between 80 and $90 \%$ of the pure protoplasts accumulated at a density of $1.11 \mathrm{~g} \mathrm{~cm}^{-3}$, whereas the contaminating structures gathered in layers of higher densities.

Radioactive labelling. [ $\left.{ }^{3} \mathrm{H}\right] \mathrm{Dansyl}$ chloride and $\mathrm{Na}^{125} \mathrm{I}$ were used as artificial markers of the plasma membrane (see Fig. 1). Both compounds react selectively and covalently under certain conditions with various amino acid residues of the plasma-membrane proteins accessible from the outside (Schibeci et al., 1973; Hubbard \& Cohn, 1976). Dansyl chloride binds to free amino acid groups only at alkaline $\mathrm{pH}$ values between $9 \cdot 0$ and $\mathbf{9 \cdot 2}$ (Marriott, 1975; Lewis \& Patel, 1978). This is critical for the specificity of plasma membrane labelling. Even if the dansyl chloride penetrates the plasma membrane (cf. Hubbard \& Cohn, 1976) it cannot label intracellular membranes since the cytosol of $M$. reukaufii has a pH of 6.2 (Aldermann \& Höfer, 1981). The iodination of tyrosine residues of plasma-membrane proteins occurs at pH 7.5 in the presence of $\mathrm{H}_{2} \mathrm{O}_{2}$ and lactoperoxidase (Phillips \& Morrison, $1970 ; 1971$ ). The size of lactoperoxidase molecules (mol. wt 78000) prevents their diffusion into the cells and thus any nonspecific labelling of intracellular membranes.

Lysis of protoplasts. The protoplasts were lysed as indicated in Fig. 1. In addition to strict control of the temperature, $\mathrm{pH}$ and volume of the lysing medium, it was important to use correct concentrations of both $\mathrm{MgCl}_{2}$ and EDTA. Because $\mathrm{Mg}^{2+}$ stabilizes membranes (Da Silveira et al., 1977; Lewis et al., 1978), concentrations higher than $0.5 \mathrm{~mm}$ retarded lysis of the protoplasts and led to aggregation of the membranes. EDTA concentrations above $5 \mathrm{~mm}$ caused the viscosity of the lysate to increase. Optimum lysis was achieved by a $5 \mathrm{~min}$ incubation in a medium consisting of $0.4 \mathrm{M}$-sorbitol, $0.2 \mathrm{mM}-\mathrm{MgCl}_{2}$ and $1 \mathrm{mM}$-EDTA at $\mathrm{pH} 7.0$ and $4^{\circ} \mathrm{C}$.

Fractionation of membranes. The separation after lysis of the homogenate into its membrane components was achieved by two methods. Firstly, by two successive centrifugations in a Beckman L2-75B ultracentrifuge (SW27 rotor) at $75000 \mathrm{~g}$ for $8 \mathrm{~h}$ on a combined discontinuous/continuous sucrose density gradient $(1 \mathrm{ml} 65 \%, 2 \mathrm{ml} \mathrm{60 \%}$, $8 \mathrm{ml} 40 \%$, and a continuous mixture from $6 \mathrm{ml} 40 \%$ and $7 \mathrm{ml} 20 \%$ sucrose, w/v). Secondly, by the attachment of microbeads according to the method described in Fig. 2.

Electron microscopy. Sample material for electron microscopy was fixed with $2 \%(w / v)$ glutaraldehyde in $12 \mathrm{~m} M \mathrm{Tr}$ ris/ $\mathrm{HCl}$ buffer $\mathrm{pH} 7.0$ and $20 \%(\mathrm{w} / \mathrm{v})$ sucrose. After washing in Tris/ $\mathrm{HCl}$ buffer the material was refixed with $2 \%(w / v)$ osmium tetroxide for $2 \mathrm{~h}$. The fixed material was dehydrated by acetone step-treatment and embedded in ERL-resin according to Spurr (1969). The ultra-thin sections were contrasted with $2 \%(w / v)$ lead citrate and $2 \%(w / v)$ uranyl acetate. The plasma membranes were additionally contrasted with phosphotungstic acid in $10 \%(w / v)$ chromic acid $\left(\mathrm{PTACrO}_{3}\right.$ ) according to Roland et al. (1972).

Analyses. The protein content of the individual membrane fractions was determined by the Lowry method.

Phospholipids and sterols were extracted with chloroform/methanol $(1: 2, v / v)$. Portions of the extracts were evaporated, mixed with $10 \%(\mathrm{w} / \mathrm{v})$ ethanolic $\mathrm{Mg}\left(\mathrm{NO}_{3}\right)_{2}$ and burned in glass test tubes on a gas burner. The ash was suspended in $1 \mathrm{ml} 0.5 \mathrm{M}-\mathrm{HCl}$ and extracted in a boiling water bath for $15 \mathrm{~min}$. The content of inorganic phosphate in the extracts was determined as in the ATPase assay (Serrano, 1978). The content of sterols in the chloroform/methanol extracts was analysed by the cholesterol-test-combination (CHOP-PAP-method, Boehringer). 


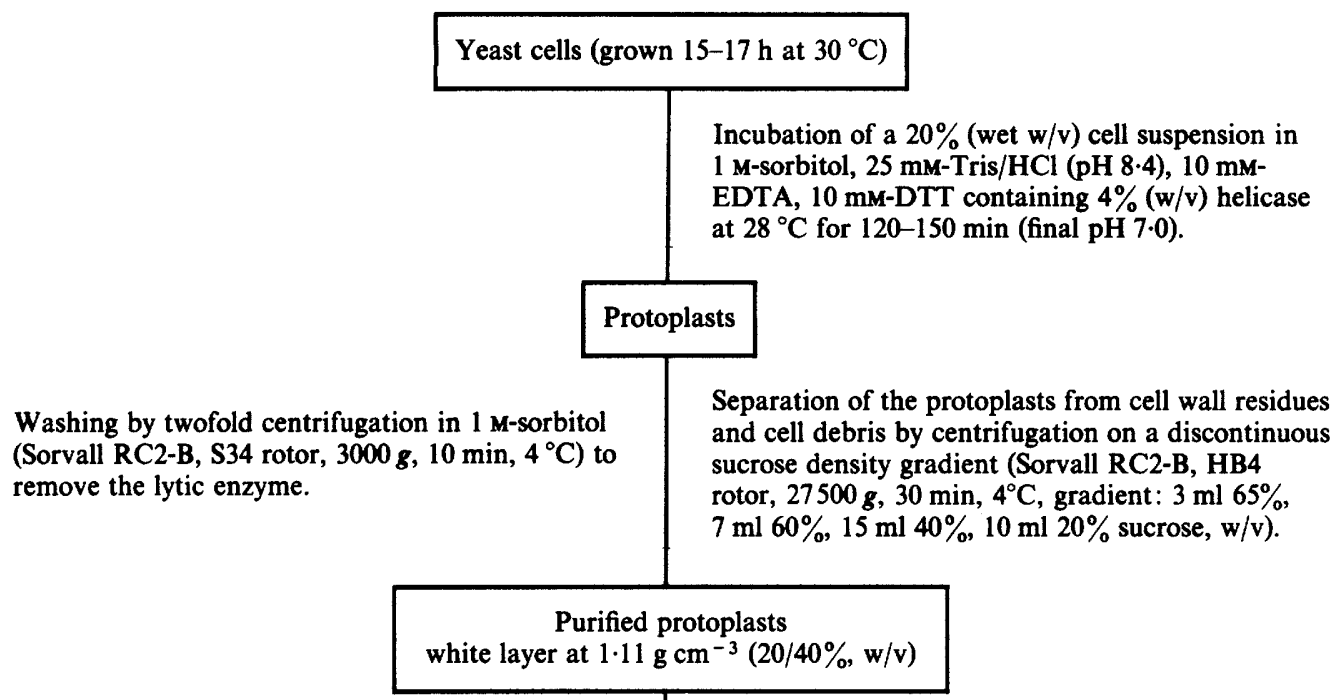

Dansylation: $25 \%(\mathrm{v} / \mathrm{v})$ protoplast suspension in $20 \mathrm{ml}$ $1 \mathrm{M}$-sorbitol containing $0.3 \mathrm{M}$-potassium phosphate buffer (pH 9.2) was incubated with $20 \mu \mathrm{Ci}$ $\left[{ }^{3} \mathrm{H}\right.$ ]dansyl chloride for $30 \mathrm{~min}$ at $20^{\circ} \mathrm{C}$, and washed six times in the buffer (Sorvall RC2-B, SS34 rotor, $3000 \mathrm{~g}, 10 \mathrm{~min}, 4^{\circ} \mathrm{C}$ ).
Iodination: $25 \%(\mathrm{v} / \mathrm{v})$ protoplast suspension in $1 \mathrm{M}$ sorbitol containing $0.1 \mathrm{M}$-potassium phosphate buffer (pH 7.5) was incubated with $3.75 \mu \mathrm{g}$ lactoperoxidase $\mathrm{ml}^{-1}, 10 \mu \mathrm{Ci} \mathrm{Na}{ }^{125} \mathrm{I}$ and $0.03 \%$ (w/v) $\mathrm{H}_{2} \mathrm{O}_{2}$ (added subsequently at $3 \mathrm{~min}$ intervals) for $30 \mathrm{~min}$ at $25^{\circ} \mathrm{C}$, and washed three times in the buffer (Sorvall RC2-B, SS34 rotor, $3000 \mathrm{~g}, 10 \mathrm{~min}$, $4{ }^{\circ} \mathrm{C}$ ).

Radioactively labelled protoplasts

Lysis of the protoplasts: $5-7 \%(\mathrm{v} / \mathrm{v})$ protoplast suspension was incubated in $0.4 \mathrm{M}$-sorbitol, containing $5 \mathrm{~mm}-\mathrm{Tris} / \mathrm{HCl}$ (pH 7.2), $0.2 \mathrm{mM}-\mathrm{MgCl}_{2}$, $1 \mathrm{mM}$-EDTA for 5-7 $\mathrm{min}$ at $4^{\circ} \mathrm{C}$.
The lysed cells were centrifuged in Sorvall RC2-B, SS34 rotor, at $27000 \mathrm{~g}$ for $30 \mathrm{~min}$ at $4^{\circ} \mathrm{C}$. The pellet was resuspended in $5 \mathrm{mM}-\mathrm{Tris} / \mathrm{HCl}(\mathrm{pH} \mathrm{7-2})$ and $20 \%(w / v)$ sucrose.

Cell membrane homogenate

Fractionation on sucrose density gradient in two steps according to Methods.

Fig. 1. Preparation of protoplasts, and their radioactive labelling and osmotic lysis.

Enzymes. ATPase activity (EC 3.6.1.3) was measured as described by Serrano (1978). The inhibitors of ATPase, oligomycin $\left(20\right.$ or $\left.25 \mu \mathrm{g} \mathrm{ml}^{-1}\right)$ and vanadate $(1 \mathrm{mM})$, were added to the reaction mixture at $30^{\circ} \mathrm{C} 5 \mathrm{~min}$ before adding the ATP.

Cytochrome $c$ oxidase activity (EC 1.9.3.1) was determined by measuring the decrease of absorbance of reduced cytochrome $c$ at $540 \mathrm{~nm}$. The reaction mixture contained $400 \mathrm{mM}$-sucrose, $25 \mathrm{~mm}$-imidazole/ $\mathrm{HCl}, 0.2 \mathrm{mM}$ EDTA, $0.02 \%(w / v)$ mercaptoethanol, $20 \mu \mathrm{l}$ reduced cytochrome $c\left(50 \mathrm{mg} \mathrm{ml}^{-1}\right)$ and 20 to $50 \mu 1 \mathrm{membrane}$ sample in a total volume of $3 \mathrm{ml}, \mathrm{pH} \mathrm{7.0.}$

Chitin synthase activity (EC 2.4.1.16) was estimated according to Cabib (1972) and Merkel et al. (1980).

$\alpha$-Mannosidase activity (EC 3 2.1.24) was measured by a modification of the method of van der Wilden et al. (1973). To $500 \mu l$ of $200 \mathrm{~mm}$-sodium acetate buffer (pH 5.0) were added $100 \mu l p$-nitrophenol- $\alpha$-mannoside $\left(2 \mathrm{mg} \mathrm{ml}^{-1}\right.$ ) and $200 \mu \mathrm{l} \mathrm{membrane} \mathrm{samples.} \mathrm{The} \mathrm{reaction} \mathrm{was} \mathrm{stopped} \mathrm{after} 200 \mathrm{~min}$ by the addition of $3 \mathrm{ml} 0.2 \mathrm{M}-$ $\mathrm{Na}_{2} \mathrm{CO}_{3}$ dissolved in $0 \cdot 1 \mathrm{M}-\mathrm{NaOH}$.

One unit (U) of enzyme activity is defined as $1 \mu \mathrm{mol}$ substrate transformed $\mathrm{min}^{-1}$. 


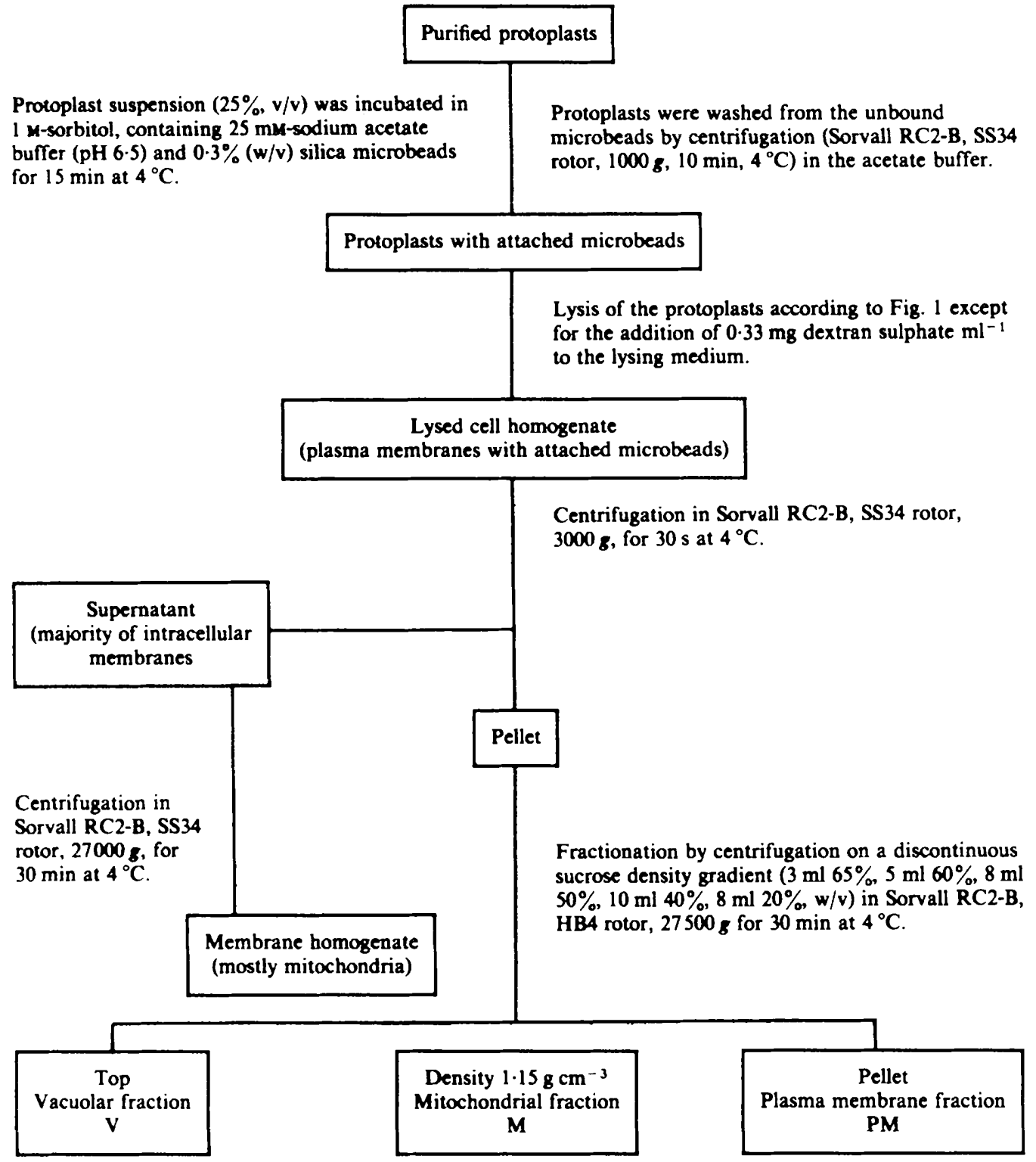

Fig. 2. Separation of plasma membranes by means of silica microbeads.

Chemicals. Oligomycin, DTT, ergosterol, $N$-acetylglucosamine, UDP- $N$-acetylglucosamine, trypsin, trypsininhibitor, p-nitrophenyl- $\alpha$-mannoside, imidazole, cytochrome $c$ and dextran sulphate were from Sigma; lyophilized helicase was from Reactifs Industrie Biologique Française, Villeneuve-la-Garenne, France; enzymes, coenzymes, nucleotides, and the cholesterol-test-combination were obtained from Boehringer; sorbitol was from Baker Chemicals, Gross-Gerau, Germany; ortho-vanadate was from ICN Pharmaceuticals Inc., Plainview, NY, USA; the microbeads ( $30 \mathrm{~nm}$ diameter, relative density $2.5 \mathrm{~g} \mathrm{~cm}^{-3}$ ) were kindly supplied by Dr B. Jacobson, University of Massachusetts, MA, USA. All other chemicals were products of Merck.

\section{RESULTS}

Isolation of the plasma-membrane fraction and evidence for a plasma-membrane-bound ATPase

The protoplasts from $M$. reukaufi cells were completely free from cell wall residues, due to the 


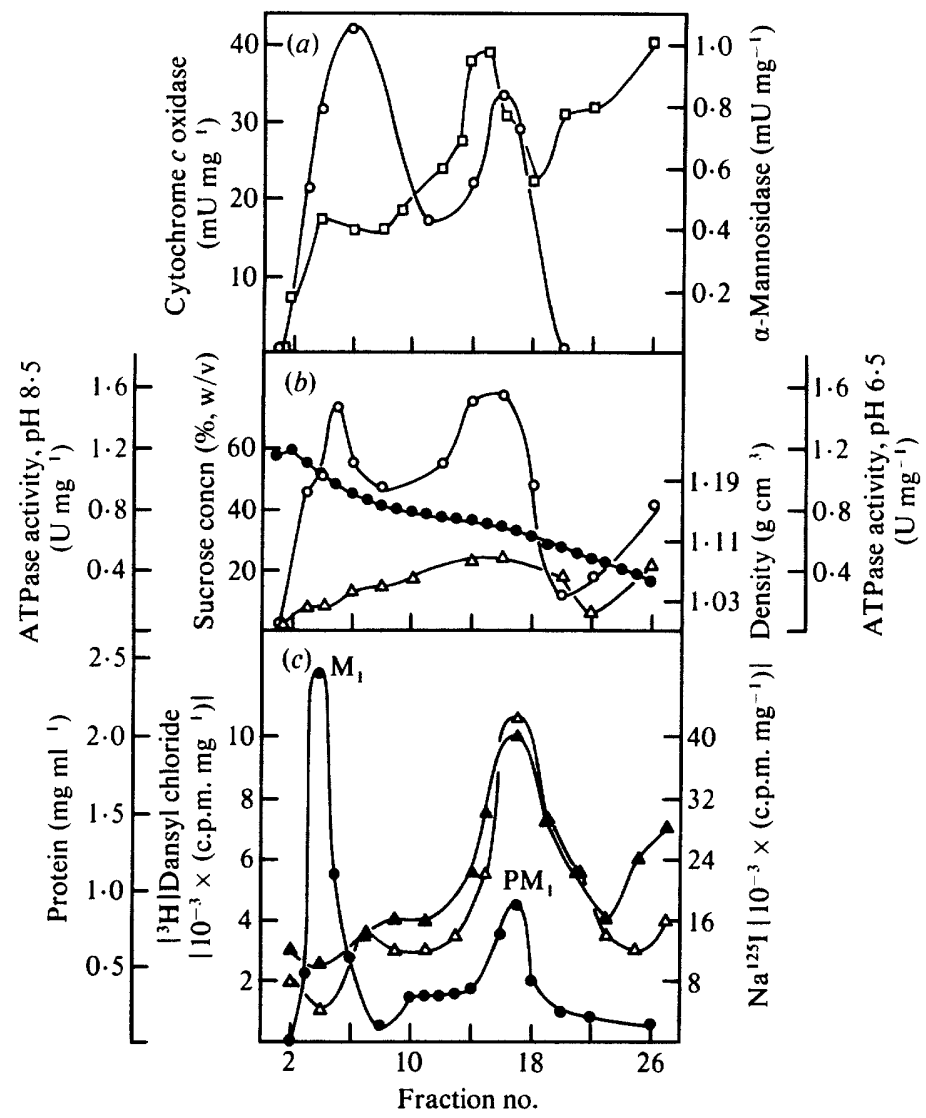

Fig. 3. Distribution of the membrane markers and of ATPase activities in fractions after the first centrifugation on a sucrose density gradient. Experimental conditions as in Methods. (a) $\bigcirc$, Cytochrome $c$ oxidase; $\square, \alpha$-mannosidase. (b) $\bigcirc$, ATPase pH 8.6; $\bigcirc$, density and sucrose concentration; $\triangle$, ATPase pH 6.5. (c) $\triangle,\left[{ }^{3} \mathrm{H}\right]$ Dansyl chloride radioactivity; $\Delta, \mathrm{Na}^{125}$ I radioactivity;, , protein.

method of protoplast evolution. Helicase produced a terminal or lateral opening, from which the protoplast emerged, appearing first as a bubble then as a complete plasma sphere. The empty cell walls were digested only by prolonged incubation.

An approximately pure plasma-membrane fraction was isolated by two successive density gradient centrifugations (see Methods). The following markers were used to identify the plasma membrane: chitin synthase activity, protein :phospholipid ratio, and, more accurately, the distribution of $\left[{ }^{3} \mathrm{H}\right]$ dansyl chloride and $\mathrm{Na}^{125} \mathrm{I}$. Cytochrome $c$ oxidase and $\alpha$-mannosidase activities were measured to determine the contamination of the plasma-membrane fraction with other intracellular membranes.

The cell lysate was separated into two distinct protein peaks by the first centrifugation step (Fig. $3 c$ ). About $20 \%$ of the total protein of the cell membrane homogenate accumulated in the lighter layer at a density of $1.13 \mathrm{~g} \mathrm{~cm}^{-3}$. Since this protein peak contained most of the radioactive label, it therefore contained the majority of the plasma membrane material, designated $\mathbf{P M}_{1}$. This layer of the gradient also had a high specific activity of chitin synthase (3.1 times greater than the total in the cell-membrane homogenate), an ATPase activity at $\mathrm{pH} 6.5$ and a protein :phospholipid ratio of 2 . The distribution of the $\alpha$-mannosidase activity showed that the tonoplast membrane of $M$. reukaufii was of equal or slightly lower density than the plasma membrane.

The heavier layer, at a density of $1.16 \mathrm{~g} \mathrm{~cm}^{-3}$, contained about $50 \%$ of the total protein of the 


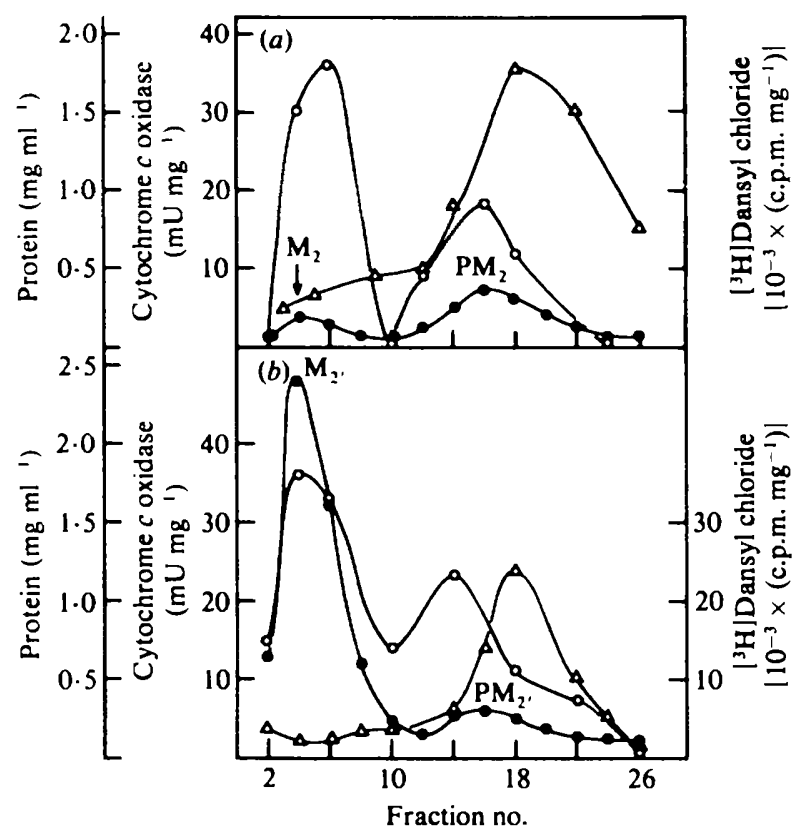

Fig. 4. Distribution of the membrane markers after the second centrifugation of each fraction, $\mathbf{M}_{1}$ and $\mathbf{P M}_{1}$, from Fig. 3 on a sucrose density gradient. (a) Analysis of the sucrose gradient after centrifugation of the lighter particle layer, $\mathbf{P M}_{1}$. (b) Analysis of the sucrose gradient after centrifugation of the heavier particle layer, $M_{1}$. The sucrose gradients were formed as for Fig. 3. $\Delta,\left[{ }^{3} \mathrm{H}\right]$ Dansyl chloride radioactivity; $O$, cytochrome $c$ oxidase; 0 , protein.

cell membrane homogenate and correlated with a high specific activity of cytochrome $c$ oxidase and an ATPase with maximum activity at pH 8.5. These two enzyme markers were characteristic of mitochondria, designated $\mathrm{M}_{1}$ (Fig. $3 a, b$ ).

A subsequent centrifugation of the two membrane fractions, the plasma membrane $\left(\mathrm{PM}_{1}\right)$ and the mitochondrial layer $\left(\mathbf{M}_{1}\right)$, on two separate density gradients of equal composition resulted in the same pattern of two distinct membrane layers on each gradient (Fig. 4). Whereas the first centrifugation had resulted in a twofold accumulation of the radioactivity in the plasmamembrane fraction, the purification was significantly increased by the second centrifugation $\left(\mathrm{PM}_{2}\right)$. Correspondingly, contamination by cytochrome $c$ oxidase was decreased. The specific activity of the cytochrome $c$ oxidase of the heavier (mitochondrial) fraction, $M_{2}$, was increased after the second centrifugation.

The pH-dependence of the ATPase activity in all membrane fractions was measured. The mitochondrial membrane fractions showed a pH-optimum for ATPase activity at 8.5. Oligomycin inhibited the ATPase of fraction $M_{1}$ by $85 \%$ and that of the two combined fractions after the second centrifugation, $\mathbf{M}_{2}+\mathbf{M}_{2^{\prime}}$, by $90 \%$ (Fig. 5). The plasma-membrane fractions had an ATPase with maximum activity at pH 6.5, which was inhibited by oligomycin by $48 \%$ in fraction $\mathbf{P M}_{1}$ and by only $11 \%$ in $\mathbf{P M}_{2}+\mathbf{P M}_{2}$, (Fig. 5). The decrease of oligomycin sensitivity demonstrates the degree of further purification of $\mathrm{PM}_{2}$, by the second centrifugation. The oligomycin-sensitive ATPase activity at $\mathrm{pH} 8.5$ of the combined plasma-membrane fractions, $\mathbf{P M}_{2}+\mathbf{P M}_{2}$, correlated with their residual cytochrome $c$ oxidase activity (cf. Fig. 4) and corresponded to about $50 \%$ contamination with mitochondrial protein.

On the basis of these results and against the background of published data for purified plasma membranes from other organisms (Fuhrmann et al., 1976; Nurminen et al., 1976; Bowman \& Slayman, 1977; Delhez et al., 1977; Scarborough, 1977; Ahlers et al., 1978; Serrano, 1978; Peters \& Borst-Pauwels, 1979; Merkel et al., 1980; Welten-Verstegen et al., 1980; Blasco et al., 1981) we 


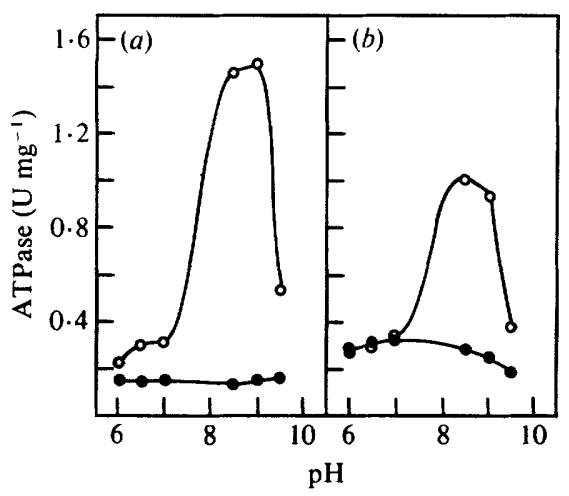

Fig. 5. pH-dependence of ATPase activity in membrane fractions after the second centrifugation on sucrose density gradient in the absence $(O)$ and in the presence $(O)$ of oligomycin $\left(20 \mu \mathrm{g} \mathrm{ml}^{-1}\right)$. (a) Combined layers $\mathbf{M}_{2}+\mathbf{M}_{2}$. (b) Combined layers $\mathbf{P M}_{2}+\mathbf{P M}_{2}$.

concluded that the oligomycin-insensitive ATPase with a pH-optimum of 6.5 was an intrinsic enzymic marker of the plasma membrane. The other ATPase with a pH-optimum of 8.5 and high oligomycin sensitivity was characteristic of the mitochondrial membrane fraction.

Preparation of the plasma-membrane fraction by means of silica microbeads

The attachment of silica microbeads to the outer surface of intact protoplasts made the separation of the plasma membrane much simpler: the density of the plasma membrane was effectively increased so that a single gradient centrifugation gave a distinctly better purification of the plasma-membrane fraction.

The silica microbeads $\left(30 \mathrm{~nm}\right.$ diameter, relative density $\left.2.5 \mathrm{~g} \mathrm{~cm}^{-3}\right)$ have a surface charge which depends on the $\mathrm{pH}$ of the surrounding medium, causing them to bind to the charged surface of the protoplasts (Chaney \& Jacobson, 1983; Schmidt et al., 1983). The association of microbeads with protoplasts could be traced both in phase-contrast and electron microscopy by cell aggregation, since microbeads associate not only with the protoplasts, but also with each other, thus creating bridges between neighbouring protoplasts.

The aggregated protoplasts were lysed after residual unattached microbeads had been washed off (see Fig. 2). The lysing medium contained a small amount of dextran sulphate to neutralize any free charge still on the microbeads. Due to the aggregated state of the plasma membranes they could be spun down by simple centrifugation at $3000 \mathrm{~g}$ and thus separated from the majority of all other intracellular components, mainly mitochondria (Fig. 6a). A subsequent density gradient centrifugation of the resuspended pellet resulted in three membrane layers (Fig. $6 b$ ). The top of the gradient contained very little, the pellet the majority of the applied material. Biochemical analysis of the three layers showed the presence of plasma membranes in an almost pure state in the pellet, as indicated by the following three measurements: 1 , maximum radioactivity from the artificial plasma-membrane marker $\left[{ }^{3} \mathrm{H}\right]$ dansyl chloride; 2, ATPase activity at $\mathrm{pH} 6.5$ sensitive to vanadate and insensitive to oligomycin; 3 , a protein : sterol ratio of 1.4 . These parameters indicated an approximately threefold purification of the plasma-membrane fraction as compared with the pellet after the first simple centrifugation. According to the specific activity of cytochrome $c$ oxidase, and the specific activity of oligomycin-sensitive ATPase at $\mathrm{pH} 8.5$, the plasma-membrane fraction was contaminated at most by $20 \%$ by mitochondrial protein.

The middle protein layer $(\mathrm{M})$ on the density gradient was enriched with mitochondria, as indicated by a high cytochrome $c$ oxidase activity and a high activity of the oligomycin-sensitive ATPase at $\mathrm{pH} 8.5$. This protein fraction also had a high oligomycin-insensitive ATPase activity at pH 6.5. However, the presence of this ATPase could not be due to contamination by plasma membranes, since the radioactivity of this fraction was very low. The same conclusion can be 


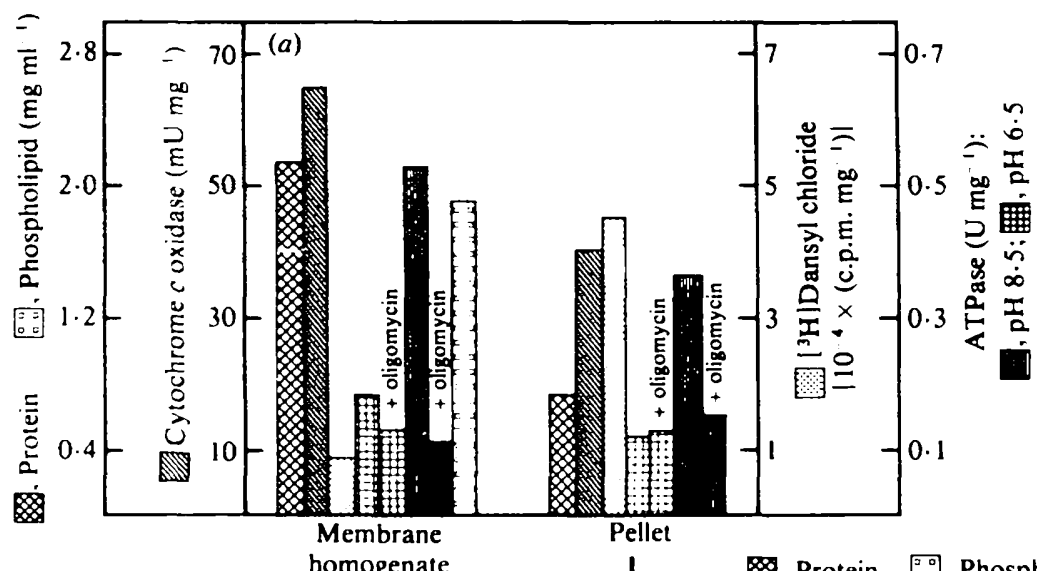

Membrane
homogenate

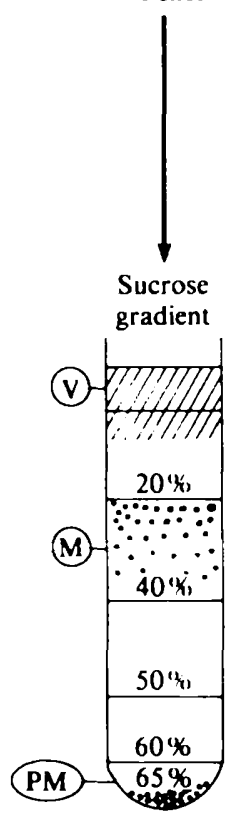

Protein 勭, Phospholipid

Sterols ( $\mathrm{mg} \mathrm{ml}{ }^{\prime}$ )

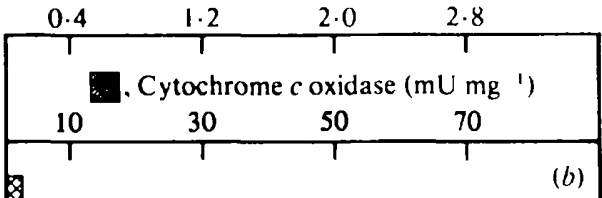

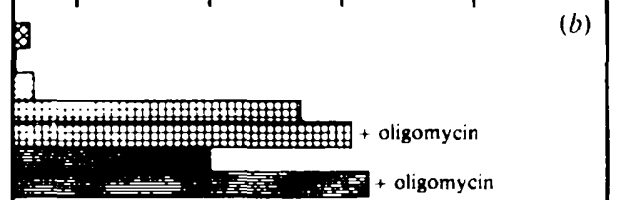

\section{m}

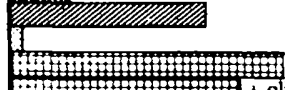

+oligomycin

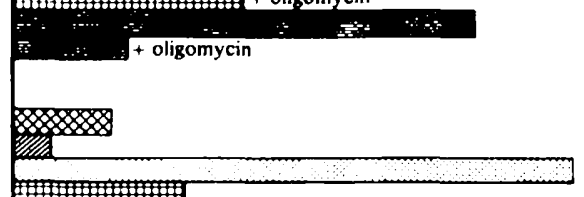

_ \#

+ vanadate

- oligomycin

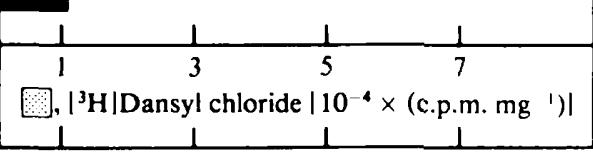

$0 \cdot 1$

0.3

$0 \cdot 5$

0.7

ATPase $\left(\mathrm{U} \mathrm{mg}^{-1}\right): \square$ pH 8.5;

Fig. 6. Distribution of the membrane markers after bw-speed centrifugation of the lysed cell homogenate $(35 \mathrm{ml})$ at $3000_{g}$ in a Sorvall RC2-B centrifuge, SS34 rotor for $30 \mathrm{~s}(a)$, followed by centrifugation of the resuspended prepurified pellet $(6 \mathrm{ml})$ on a discontinuous sucrose density gradient (see Methods) at $27500 \mathrm{~g}$ in an $\mathrm{HB} 4$ rotor for $30 \mathrm{~min}(b)$. The membrane homogenate in (a), of total volume $6 \mathrm{ml}$, was obtained by further centrifugation of the $3000 \mathrm{~g}$ supernatant in an SS34 rotor at $27000 \mathrm{~g}$ for $30 \mathrm{~min}$. On the basis of the analysis of various membrane markers the heaviest membranes on the bottom of the centrifuge tube were ascribed to plasma membranes, PM; the middle layer comprised mostly mitochondrial membranes, $\mathbf{M}$, contaminated with other membrane particles (vacuolar?); and the light membrane particles on the top of the gradient were attributed to vacuolar membranes, $V$. The volume of the individual fractions was $3 \mathrm{ml}$. 


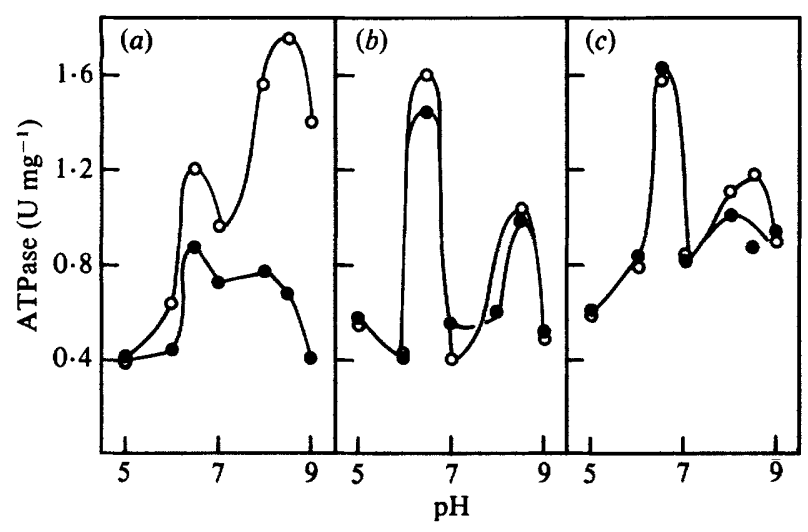

Fig. 7. pH-dependence of ATPase activity in membrane fractions after fractionation by means of silica microbeads. The experimental procedure was as described for Fig. 6. O, ATPase activity in the absence of oligomycin; , ATPase activity in the presence of $20 \mu \mathrm{g}$ oligomycin $\mathrm{ml}^{-1}$. (a) Membrane homogenate from the supernatant after the low-speed centrifugation. Fraction $\mathbf{M}$ (mitochondrial membranes) showed the same activity spectrum. (b) Fraction V (vacuolar membranes). (c) Fraction PM (plasma membranes).

drawn for the ATPase activity of the protein layer (V) in the top of the density gradient (Fig. $6 b$ ). On the basis of these results a third ATPase activity is postulated in the membrane homogenate of lysed protoplasts from $M$. reukaufii and assigned to the tonoplast membrane, since the $\alpha$ mannosidase (Fig. 3) showed a maximum activity in the layer at a density below $1.16 \mathrm{~g} \mathrm{~cm}^{-3}$. Furthermore, a high content of vacuoles in $M$. reukaufi was indicated by electron microscopy.

The $\mathrm{pH}$-dependence of the three different ATPase activities and their sensitivities to oligomycin are shown in Fig. 7. The mitochondrial ATPase was the main protein component of the supernatant after the first centrifugation (Fig. 7a), and of the middle layer (M) after the density gradient centrifugation (not shown). The ATPase activity of both protein fractions had an optimum at $\mathrm{pH} 8.5$ and was inhibited by $55 \%$ by oligomycin. The ATPase of the vacuolar fraction (V) from the top of the density gradient had two pH-maxima, at 6.5 and 8.5 , and was insensitive to, or slightly stimulated by oligomycin throughout the $\mathrm{pH}$-region tested (Fig. $7 b$ ). The ATPase of the plasma-membrane fraction, PM, reached its maximum activity at $\mathrm{pH} 6.5$ and was completely insensitive to oligomycin (Fig. $7 c$ ). However, it was specifically inhibited by 1 mM-vanadate (Fig. 6b).

The conclusions drawn on the basis of biochemical characterization of the individual membrane fractions were confirmed by electron microscopy (Fig. 8). The vacuolar fraction (V) contained membrane vesicles, which were not contrasted by $\mathrm{PTACrO}_{3}$ (Fig. 8a). The mitochondrial fraction, $M$, consisted of numerous intact mitochondria together with empty membrane envelopes, which probably originated from mitochondria, but possibly also from tonoplast membranes (Fig. 8b). The plasma-membrane fraction comprised high amounts of membrane vesicles contrasted by $\mathrm{PTACrO}_{3}$, which were frequently covered by a layer of associated microbeads and only slightly contaminated by mitochondria-like structures (Fig. $8 \mathrm{c}$ ).

\section{DISCUSSION}

The preparation of true protoplasts from $M$. reukaufi cells allowed a gentle osmotic cell lysis followed by isolation of plasma membranes on a sucrose density gradient. It enabled us also to label specifically the outside surface of the plasma membrane with either $\left[{ }^{3} \mathrm{H}\right]$ dansyl chloride or $\mathrm{Na}^{125} \mathrm{I}$, as used for other organisms (Schibeci et al., 1973; Mariott, 1975; Durán et al., 1975; Rank et al., 1978; Santos et al., 1978; Zingales et al., 1979). 

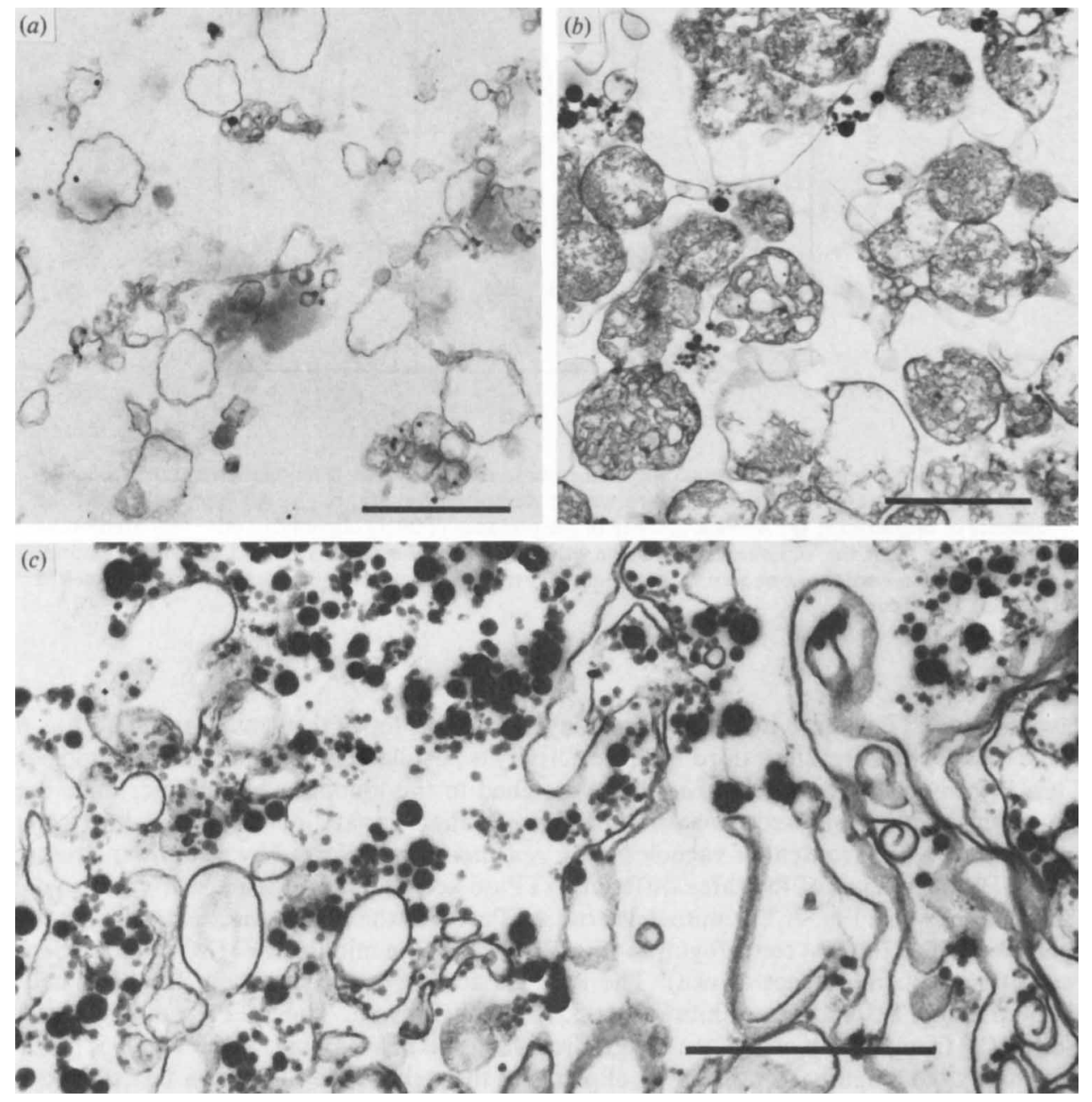

Fig. 8. Electron micrographs of $(a)$ the vacuolar-membrane fraction; $(b)$ the mitochondrial membrane fraction; (c) the plasma membrane fraction. The plasma membranes were contrasted with $\mathrm{PTACrO}_{3}$. Bar markers $1 \mu \mathrm{m}$.

A crucial point in the process of the membrane fractionation was the lysis of the protoplasts. The experimental conditions were optimized so that the lysis proceeded completely and quickly. Under these optimal conditions the plasma membranes vesiculated so that contamination with other intracellular membranes was reduced. Nevertheless, the two layers after the first density gradient centrifugation were cross-contaminated to a considerable extent (Fig. 3).

The second density gradient centrifugation, of both the plasma membrane fraction, $\mathbf{P M}_{1}$, and the mitochondrial fraction, $\mathbf{M}_{1}$, increased the purity of the individual fractions. The $\mathbf{P M}_{2}$ fraction was much less contaminated with mitochondria. The second centrifugation step with the $M_{1}$ fraction was important, since the plasma membranes in this fraction were further separated from the mitochondria, again at a density of $1.13 \mathrm{~g} \mathrm{~cm}^{-3}$ (Fig. 4). The portion of plasma membrane protein thus obtained was approximately equal to that from the second centrifugation of $\mathbf{P M}_{1}$.

This second purification step was also important for the identification and characterization of the ATPase activities of the individual membrane fractions (Fig. 5). The ATPase of the 
mitochondria had a pH-optimum of 8.5 and was $90 \%$ inhibited by oligomycin, whereas the plasma-membrane ATPase had a pH optimum of 6.5 and was inhibited by oligomycin by only $10 \%$. The specific inhibitor of the plasma-membrane ATPase was vanadate (Fig. $6 b$ ). Thus, the ATPase of $M$. reukaufii showed the same activity pattern as those already known from other fungi (Bowman et al., 1978; Serrano, 1978; Ahlers et al., 1978; Peters \& Borst-Pauwels, 1979; Welten-Verstegen et al., 1980; Ahlers, 1981; Blasco et al., 1981). On the basis of the present results and those in the literature, the oligomycin-insensitive, vanadate-sensitive ATPase at pH 6.5 was recognized as a true intrinsic enzyme marker of the plasma membrane of $M$. reukaufii.

The use of silica microbeads simplified the preparation and considerably enhanced the purity of the isolated plasma membranes. Contamination with other intracellular membranes of the plasma membrane fraction did not exceed $20 \%$, a satisfactory result, considering that $M$. reukaufii cells are filled with mitochondria and vacuoles. The contamination was about onethird of that obtained by two successive density gradient centrifugations. When comparing the purification factor of 3 for the plasma membrane fraction from $M$. reukaufii with results in the literature for other fungi (Bowman \& Slayman, 1977; Ahlers et al., 1978; Blasco et al., 1981; Goffeau \& Slayman, 1981) it should be remembered that it was calculated in relation to a prepurified membrane homogenate, from which the cell walls, cell debris, most of the intracellular organelles and the soluble cytoplasmic proteins had already been removed.

The purification factor for the plasma-membrane fractions was consistently lower when calculated from the specific activity of ATPase at $\mathrm{pH} 6.5$ rather than from the specific radioactivity (Fig. 6). This discrepancy may be due to the presence of other ATPases active at pH 6.5 in the reference homogenate or to spontaneous formation of 'right-side-out' vesicles, whose ATPase was not recorded by the activity test (cf. Scarborough, 1976; Quail, 1979). This limitation is, however, not valid for the other ATPases (of mitochondria and tonoplasts).

A vacuolar ATPase in yeasts has so far been neglected by other authors because of its expected low activity (Ahlers et al., 1978; Ohsumi \& Anraku, 1981). However, the fractionation of $M$. reukaufii membranes made it clear that apart from the plasma membrane and the mitochondrial ATPases there was still another very active ATPase at the top of the sucrose density gradient. It was oligomycin insensitive and showed two pH-maxima, at 6.5 and 8.5 (Figs 6 and 7). This ATPase activity could not be accounted for either by mitochondrial contamination (due to lack of both oligomycin-sensitivity of the ATPase and the cytochrome $c$ oxidase activity of the protein fraction) or by plasma-membrane contamination (no incorporated radioactivity in the protein fraction) and was, therefore, assigned to the tonoplast membrane. The $\alpha$-mannosidase activity measured in the protein fraction from the top of the gradient (density region 1.15-1.11 of Fig. 3) was in accord with this assignment. The existence of a vacuolar ATPase would also account for the high oligomycin-insensitive ATPase activity at $\mathrm{pH} 6.5$ of the mitochondrial fraction, which could not be due to contamination by plasma-membrane (lack of incorporated radioactivity) (Figs $6 b$ and 7 ).

The preparative method using silica microbeads described in this paper represents a simple procedure for isolation of a sufficiently pure plasma-membrane fraction which can be used as a starting material for further investigation of active transport processes at the plasma membrane.

We are indebted to Dr B. Buchen of this Institute for making the electron micrographs. Our thanks are due to Dr B. Jacobson for supplying us generously with the silica microbeads and to Dr R. Schmidt of the Free University of Berlin for valuable discussion during the work with them. This work was supported by the Deutsche Forschungsgemeinschaft (grant no. Ho 555).

\section{REFERENCES}

AHLERs, J. (1981). Temperature effects on kinetic properties of plasma membrane ATPase from the yeast Saccharomyces cerevisiae. Biochimica et biophysica acta 649, 550-556.
Ahlers, J., AHr, E. \& Seyfarth, A. (1978). Kinetic characterisation of plasma membrane ATPase from Saccharomyces cerevisiae. Molecular and Cellular Biochemistry 22, 39-49. 
AldermanN, B. \& HOFER, M. (1981). The active transport of monosaccharides by the yeast Metschnikowia reukaufii: evidence for an electrochemical gradient of $\mathrm{H}^{+}$across the cell membrane. Experimental Mycology 5, 120-132.

Anderson, F. B. \& Millbanx, J. W. (1966). Protoplast formation and yeast cell wall structure. The action of the enzyme of the snail, Helix pomatia. Biochemical Joumal 99, 682-687.

Blasco, F., Chapuls, J. P. \& Giordani, R. (1981). Characterisation of the plasma membrane ATPase of Candida tropicalis. Biochemie 63, 507-514.

Bowman, B. J. \& Slayman, C. W. (1977). Characterisation of plasma membrane ATPase of Neurospora crassa. Journal of Biological Chemistry 252, 33573363.

Bowmun, B. J., Mannzer, S. E., Allen, K. E. \& Slayman, C. W. (1978). Effects of inhibitors on the plasma membrane and mitochondrial ATPases of Neurospora crassa. Biochimica et biophysica acta 512, 12-28.

CABIB, E. (1972). Chitin synthetase system. Methods in Enzymology 28B, 572-581.

ChaneY, L. K. \& JACOeson, B. S. (1983). Coating cells with colloidal silica for high yield isolation of plasma membrane sheets and identification of transmembrane proteins. Joumal of Biological Chemistry 258, 10062-10082.

Da Sil veira, J. F., Zngales, B. \& Coll, W. (1977). Characterisation of an adenylyl cyclase activity in particulate preparations from epimastigote forms of Trypanosama cruzi. Biochimica et biophysica acta 481 , $722-733$

Delhiez, J., Dufour, J. P., Thines, D. \& Goffrau, A. (1977). Comparison of the properties of plasma membrane bound and mitochondria bound ATPase in the yeast Schizosaccharomyces pombe. European Joumal of Biochemistry 79, 319-328.

Durín, A., Bowers, B. \& Cabis, E. (1975). Chitin synthetase zymogen is attached to the yeast plasma membrane. Proceedings of the National Academy of Sciences of the United States of America 72, 39523955.

EDDY, A. A. (1982). Mechanisms of solute transport in selected eukaryotic micro-organisms. Advances in Microbial Physiology 23, 2-78.

FukruanN, G. F., BOEKA, C. \& THEUVENENT, A. P. R. (1976). Sugar transport and potassium permeability in yeast plasma membrane vesicles. Biochimica et biophysica acta 433, 583-596.

Galaratty, D. W. \& Northoote, D. H. (1977). The isolation of plasma membrane from protoplasts of soybean suspension cultures. Journal of Cell Science 24, 295-310.

Goffenu, A. \& Slayman, C. W. (1981). The proton translocating ATPase of the fungal plasma membrane. Biochimica et biophysica acta 639, 197223.

HAROLD, F. M. (1977). Membranes and energy transduction in bacteria. Current Topics in Bioenergetics 6, $84-149$.

Hubbard, A. L. \& Cohn, Z. A. (1976). Specific labels for cell surfaces. In Biochemical Analysis of Membranes, vol. 12, pp. 427-501. Edited by A. H. Maddy. London: Chapman \& Hall.

LEWIS, M. J. \& PATEL, P. C. (1978). Isolation and identification of the cytoplasmic membrane from
Saccharomyces carlsbergensis by radioactive labelling. Applied and Environmental Microbiology 36, 851-856.

Lewis, M. J., Somage, A. \& Patel, P. C. (1978). Association of divalent ions with proteins of the yeast plasma membrane. Journal of Food Biochemistry 2, 169-184.

LONGLEY, R. P., ROSE, A. H. \& KNIGHTS, B. A. (1968). Composition of the protoplast membrane from Saccharomyces cerevisiae. Biochemical Joumal 108, $401-412$.

MARRIOTt, M. S. (1975). Isolation and chemical characterization of plasma membranes from the yeast and mycelial form of Candida albicans. Joumal of General Microbiology 86, 115-132.

Merkel, G. J., NaIder, F. \& Becker, J. M. (1980). Amino acid uptake by Saccharomyces cerevisiae plasma membrane vesicles. Biochimica et biophysica acta 595, 109-120.

MrTChelL, P. (1963). Molecule, group and electron translocation through natural membranes. Biochemical Society Sympasia 22, 142-168.

MrtchelL, P. (1967). Translocations through natural membranes. Adoances in Enzymology 29, 33-87.

NuRManen, T., TASKINEN, L. \& SUOMALAINEN, $H$. (1976). Distribution of membranes, especially of plasma membrane fragments, during zonal centrifugations of homogenates from glucose repressed Saccharomyces cerevisiae. Biochemical Joumal 154, $751-763$.

OrsuMn, Y. \& ANRakU, Y. (1981). Active transport of basic amino acids driven by proton motive force in vacuolar vesicles of Saccharamyces cerevisiae. Journal of Biological Chemistry 256, 2079-2082.

Perlin, D. S. \& Spanswick, R. M. (1980). Labeling and isolation of plasma membranes from corn leaf protoplasts. Plant Physiology 65, 1053-1057.

Petrers, P. H. J. \& Borst-PaUwels, G. W. F. H. (1979). Properties of plasma membrane ATPase and mitochondrial ATPase of Saccharomyces cerevisiae. Physiologia plantarum 46, 330-337.

PhILIIPS, D. R. MORrison, M. (1970). The arrangement of proteins in the human erythrocyte membrane. Biochemical and Biophysical Research Communications 40, 284-289.

Phillips, D. R. \& Morrison, M. (1971). Exposed protein on the intact human erythrocyte. Biochemistry 10, 1766-1771.

QuAI,, P. H. (1979). Plant cell fractionation. Anmual Review of Plant Physiology 30, 425-484.

RANK, G. H., Robertson, A. J. \& BuSSEY, H. (1978). The viscosity and lipid composition of the plasma membrane of multiple drug resistant and sensitive yeast strains. Canadian Joumal of Biochemistry 56, 1036-1041.

Romnson, J. D. \& Flashner, M. S. (1979). The (Na+ and $\mathbf{K}^{+}$)-activated ATPase. Enzymatic and transport properties. Biochimica et biophysica acta 549, 145-176.

Roland, J. C., Lemir, C. A. \& MorRk, D. J. (1972). Phosphotungstic acid-chromic acid as a selective electron-dense stain for plasma membranes of plant cells. Stain Technology 47, 195-200.

Santos, E., Villanuteva, J. R. \& Sentandreu, R. (1978). The plasma membrane of Saccharomyces cerevisiae. Isolation and some properties. Biochimica et biophysica acta 505, 39-54. 
Scarborough, G. A. (1976). The Neurospora plasma membrane ATPase is an electrogenic pump. Proceedings of the National Academy of Sciences of the United States of America 73, 1485-1488.

Scarborough, G. A. (1977). Properties of the Neurospora crassa plasma membrane ATPase. Archives of Biochemistry and Biophysics 180, 384-393.

Schibeci, A., Rattray, J. B. M. \& Kidby, D. K. (1973). Isolation and identification of yeast plasma membrane. Biochimica et biophysica acta 311, 15-25.

SCHMidT, R., ACKERMANN, B., KRATKY, Z., WASSERMAN, B. \& JACOBSON, B. (1983). Fast and efficient purification of yeast plasma membranes using cationic silica microbeads. Biochimica et biophysica acta 732, 421-427.

SCHWENCKe, J., MAGAÑA-SCHWENCKE, N. \& LAPORTE, J. (1977). Yeast protoplasts from stationary and starved cells: preparation, ultrastructure and vacuolar development. Annales de microbiologie 128A, 318.

SERRANO, R. (1978). Characterisation of the plasma membrane ATPase of Saccharomyces cerevisiae. Molecular and Cellular Biochemistry 22, 51-63.

SPURR, A. R. (1969). A low-viscosity epoxy resin embedding medium for electronmicroscopy. Journal of Ultrastructure Research 26, 31-43.

Thomas, K. R. \& DAVIS, B. (1980). The effect of calcium on protoplast release from species of Aspergillus. Microbios 28, 69-80.

Torres-Bauzí, L. J. \& Riggsby, W. S. (1980). Protoplasts from yeast and mycelial forms of Candida albicans. Journal of General Microbiology 119, 341349.

Verma, A. K. \& Penniston, J. T. (1981). A high affinity $\mathrm{Ca}^{2+}$-stimulated and $\mathbf{M g}^{2+}$-dependent ATPase in rat corpus luteum plasma membrane fractions. Journal of Biological Chemistry 256, 1269-1275.

Villanueva, J. R. \& Garcia-Acha, J. (1971). Production and use of fungal protoplasts. Methods in Microbiology 4, 665-718.

Welten-Verstegen, G. W., Boer, P. \& SteynPARVÉ, E. P. (1980). Lipid-mediated glycosylation of endogenous proteins in isolated plasma membrane of Saccharomyces cerevisiae. Journal of Bacteriology 141, 342-349.

WIEMREN, A. \& DÜRR, M. (1974). Characterisation of amino acid pools in the vacuolar compartment of Saccharomyces cerevisiae. Archives of Microbiology 101, 45-57.

VAN DER Wilden, W. MATile, P. H., SchellenberG, M., MeYer, J. \& Wiemken, A. (1973). Vacuolar membranes: isolation from yeast cells. Zeitschrift für Naturforschung 28C, 416-421.

WILEY, W. R. (1974). Isolation of spheroplast and membrane vesicles from yeast and filamentous fungi. Methods in Enzymology 31, 609-629.

Zingales, B., Carniol, C., Abrahamsohn, P. A. \& Colli, W. (1979). Purification of an adenyl cyclase containing plasma membrane fraction from Trypanosoma cruzi. Biochimica et biophysica acta 550, 233244. 